\title{
Sunlight Deficiency: a Reversible Cause of Low Serum Phosphate?
}

Authors

Affiliations

\section{A. H. Heald ${ }^{1,2}$, D. Radford ${ }^{2}$, S. Nair ${ }^{2}$, M. Livingston ${ }^{3}$}

${ }^{1}$ The School of Medicine and Manchester Academic Health Sciences Centre, University of Manchester, Manchester ${ }^{2}$ Department of Diabetes and Endocrinology, Leighton Hospital, Crewe

${ }^{3}$ Department of Blood Sciences, Walsall Manor Hospital, Walsall, United Kingdom

\footnotetext{
Key words

- vitamin D

- deficiency

- phosphate

- sunlight

- case
}

\section{Abstract \\ $\nabla$}

Vitamin D deficiency is associated with low circulating levels of calcium and phosphate.

A 56-year-old asymptomatic gentleman was referred with laboratory findings of undetectable serum phosphate $(<0.16 \mathrm{mmol} / \mathrm{L})$ and a history of calcified renal calculi. 25-hydroxyvitamin D (25-OHD) was low at $19.0 \mathrm{nmol} / \mathrm{L}$ (concentrations of $<30 \mathrm{nmol} / \mathrm{L}$ are indicative of vitamin $\mathrm{D}$ deficiency). Serum adjusted calcium was normal at $2.38 \mathrm{mmol} / \mathrm{L}$ (reference range (RR): $2.0-2.6$ ), as was parathyroid hormone. 24-h urine calcium excretion was elevated at $10.8 \mathrm{mmol}$ per $24 \mathrm{~h}$ (RR: 2.5-7.5), with normal 24-h urinary phosphate (RR: $12.9-42.0 \mathrm{mmol} / 24 \mathrm{~h}$ ). Renal function was normal.
On questioning, it was revealed that he worked indoors between $06.00 \mathrm{~h}$ and $15.00 \mathrm{~h}$ for approximately 24 days per month, and on rest days he went out mainly in the evenings.

Achievement of adequate sunlight exposure resulted in normalisation of 25-OHD status and serum phosphate levels. In relation to normalisation of vitamin D status, there was a reduction in urinary calcium excretion, which when elevated may have contributed to the renal calculi.

The authors propose that investigation of low phosphate or calcium levels should always include an assessment of time spent outdoors in the daytime and vitamin D status. received $\quad 12.02 .2015$

first decision 23.04.2015

accepted $\quad 21.05 .2015$

\section{Bibliography}

DOI http://dx.doi.org/

10.1055/s-0035-1554690

Published online: 2015

Exp Clin Endocrinol Diabetes

Rep 2015; 3: e11-e13

(C) J. A. Barth Verlag in

Georg Thieme Verlag KG

Stuttgart · New York

ISSN 2196-7407

\section{Correspondence}

\section{Dr. A. Heald}

Department of Diabetes and

Endocrinology

Leighton Hospital

Crewe

CW1 4Q

UK

Tel.: + 44/1270/612353

Fax: $+44 / 1270 / 273353$

adrian.heald@manchester.ac.uk

(c) 9 (1)

\section{Introduction \\ $\nabla$}

Vitamin D deficiency is very common in the UK, as described in reports over recent years $[1,2]$. Vitamin D deficiency related problems of rickets in children, and osteomalacia or increased fracture risk in adults, remain a significant public health issue, even though the links have been known since the 1920s [1-3].

Historically, the first attention to rickets, which we now know to be caused by Vitamin D deficiency, was described in England by Daniel Whistler in 1645 [4]. 6 years later Francis Glisson (1651) provided a classic description of the disease. It was described as a disease that occurred in young children, produced severe deformities and was often fatal. The condition, which was known in Europe as "the English disease", was more common in the cities than in rural areas [4]. Prior to the industrial revolution, it was associated with affluence, as the children of well-to-do families were often completely covered by clothing and were kept indoors away from sunlight.
There is now increasing evidence that vitamin $\mathrm{D}$ insufficiency may play a role in the aetiology of a number of other chronic diseases such as hypertension, cardiovascular disease and diabetes mellitus (both type 1 and type 2 ), and possibly some cancers $[1,3,5]$.

More than $90 \%$ of a person's vitamin D requirement comes from casual exposure to sunlight, with very few foods naturally containing vitamin D. When solar ultraviolet B radiation (UVB; wavelength $290-315 \mathrm{~nm}$ ) penetrates the skin, 7-dehydrocholesterol in the plasma membrane of skin cells absorbs it, resulting in the ring opening of 7-dehydrocholesterol to form pre-vitamin $D_{3}$ [6]. Pre-vitamin $D_{3}$ is thermodynamically unstable and is rapidly converted to vitamin $D_{3}$. At the latitude of London, United Kingdom, little if any vitamin $D_{3}$ is made from sunlight exposure between the middle of October and early March. Circulating vitamin $\mathrm{D}_{3}$ levels in summer are $30-100 \%$ higher than winter values [7]. Increased skin pigmentation and habitual application of topical sunscreens can reduce the number of 
UVB photons entering the skin by as much as $99 \%$, and glass absorbs all UVB. Moreover, institutionalised or house bound individuals, and those covering up virtually all of their skin with occlusive garments for religious reasons, are also at risk. Only a few natural foods, such as eel, herring and salmon, are good sources of vitamin D. Dietary vitamin D is thought to contribute only $10-20 \%$ of human vitamin D supply.

Once vitamin $\mathrm{D}_{3}$ is made in the skin, or is ingested in the diet as vitamin $\mathrm{D}_{2}$, it undergoes 25-hydroxylation in the liver to 25-hydroxyvitamin $\mathrm{D}_{3}\left(25-\mathrm{OHD}_{3}\right)$ or $25-\mathrm{OHD}_{2}$, respectively. $25-\mathrm{OHD}$ is then further hydroxylated in the kidney to $1,25-\mathrm{di}$ $\mathrm{OHD}$, the metabolically active form. This form of hydroxylated vitamin $D_{3}$ is required for both phosphate and calcium absorption in the small intestine and resorption from bone, together with actions on the parathyroid gland mediated through interaction with its specific nuclear vitamin D receptor (VDR). Recently, it has been recognised that most tissues in the body also possess the 25-OHD- $1 \alpha$-hydroxylase and thus have the capacity locally to produce 1,25-diOHD [8]. Vitamin D deficiency is associated with low circulating calcium and phosphate levels. Clinical symptoms and signs of vitamin D deficiency include muscle pain, limb girdle pain, hypocalcaemia, proximal myopathy, pathological fracture, tetany, and seizures.

Herein, the current authors report a case of an asymptomatic man whose serum phosphate deficiency was found to be secondary to vitamin $\mathrm{D}_{3}$ deficiency as a consequence of low sunlight exposure.

\section{Case Report}

$\nabla$

A 56-year-old asymptomatic man of White European origin was referred with laboratory findings of undetectable serum phosphate $(<0.16 \mathrm{mmol} / \mathrm{L})$ and a history of calcified renal calculi. $25-\mathrm{OHD}_{3}$ was low at $19.0 \mathrm{nmol} / \mathrm{L}$ (concentrations of $<30 \mathrm{nmol} / \mathrm{L}$ are indicative of vitamin $\mathrm{D}$ deficiency). The calculi had manifest in the winter months and were passed spontaneously. Our patient was on no medication at the time of presentation with the renal calculi. Serum adjusted calcium was normal at $2.38 \mathrm{mmol} / \mathrm{L}$ (reference range (RR): 2.0-2.6) as was parathyroid hormone at $2.2 \mathrm{pmol} / \mathrm{L}$ (RR: 1.1-6.9). 24-h urine calcium excretion was elevated at $10.8 \mathrm{mmol} / 24 \mathrm{~h}$ (RR: $2.5-7.5$ ) with normal 24-h urinary phosphate, although at the high end of the range (RR: $12.9-42.0 \mathrm{mmol} / 24 \mathrm{~h}$ ). Renal function was normal with both urea and creatinine within their respective reference ranges and the estimated glomerular filtration rate (eGFR) $>90 \mathrm{ml} / \mathrm{min}$. Questioning revealed that he worked indoors between $06.00 \mathrm{~h}$ and $15.00 \mathrm{~h}$ for approximately 24 days per month, and on rest days he went out mainly in the evenings. Dietician analysis revealed a normal dietary intake of calcium and of phosphorus.

\section{Management}

Sunlight exposure during the spring was encouraged. Dietitian review indicated that the low serum phosphate was not due to dietary insufficiency, and he maintained a good intake of dairy products. At the next review in early summer, 25-OHD level had improved to $56.4 \mathrm{nmol} / \mathrm{L}$ (concentrations $>50 \mathrm{nmol} / \mathrm{L}$ are indicative of vitamin D adequacy), and phosphate was near normal at $0.66 \mathrm{mmol} / \mathrm{L}$ (RR: 0.8-1.5). By mid-summer, there was complete normalisation of phosphate levels $(0.83 \mathrm{mmol} / \mathrm{L})$, with $25-\mathrm{OHD}$ remaining normal. Urinary calcium excretion decreased to $6.9 \mathrm{mmol} / 24 \mathrm{~h}$ (RR: $2.5-7.5 \mathrm{mmol} / 24 \mathrm{~h}$ ).

\section{Discussion}

$\nabla$

In this case, simply encouraging adequate sunlight exposure resulted in normalisation of vitamin D status and serum phosphate. In relation to normalisation of vitamin D status, there was a reduction of urinary calcium excretion, which when elevated may have contributed to the development of renal calculi. In the presence of severe hypophosphatemia, the 24-h urinary phosphate level was inappropriately normal (but at the high end of the reference range), suggesting renal phosphate wasting might have occurred previously. However, as the hypophosphataemia became severe, very little phosphate was then available for excretion in the urine. The circulating level of fibroblast growth factor (FGF23) was not measured and dysregulation of FGF23 function probably contributed to severe hypophosphatemia in this case.

Most experts agree that a 25-OHD level of $>50 \mathrm{nmol} / \mathrm{L}$ is the minimum level for vitamin D sufficiency. However, studies have shown that $>75 \mathrm{nmol} / \mathrm{L}$ of $25-\mathrm{OHD}$, PTH levels are at their ideal concentration [9-11].

Environmental UVB exposure is the most important source natural source of vitamin D. There is considerable controversy about the extent of sun exposure which should be recommended, given the association of skin cancers with excess UVB exposure. However, the UK National Diet and Nutrition Survey [12] demonstrated high rates of vitamin $D$ deficiency. If untreated, the associated chronic disorders place heavy burdens on the individual and on the state. It has been suggested that the equivalent of $15 \mathrm{~min}$ of mid-summer sun exposure at noon on a weekly basis is sufficient to give adequate vitamin D levels in adults throughout the year $[13,14]$. In Northern European office or factory workers, this equates to the amount of sunlight exposure achieved during casual outdoor sojourns, principally at weekends.

Our case highlights the importance of investigating low serum phosphate or calcium levels, with the need to always take a sunlight exposure history and check vitamin D status. In all patients presenting with vitamin D deficiency, it is paramount to determine the level of exposure to sunlight. One limitation in this case study was the lack of previous vitamin D levels or bone profile results.

The patient has maintained the changes to his lifestyle and continues to get optimal sunlight exposure. This non-pharmacological intervention has resulted in normalisation of his phosphate and vitamin $D$ levels. The relevance of vitamin $D$ to health needs to be recognised by all of us $[1,2]$.

\section{Funding \\ $\nabla$}

No external funding supported this study.

\section{Ethical Approval \\ $\nabla$}

Informed consent obtained.

\section{Contributors}

$\nabla$

AHH wrote the first draft of the manuscript. DR and SN were involved in data collection and contributed to the writing of the paper. ML provided scientific advice and helped with the litera- 
ture review and final drafting of the manuscript. All authors approved the final version of the manuscript.

\section{Guarantor}

AHH.

Conflict of interest: None to declare.

\section{References}

1 Health Research Forum Publishing. Sunlight, Vitamin D and Health. A report of a conference held at the House of Commons. First Edition, Ed. Oliver Gillie. Health Research Forum Occasional Reports: No 2. Available at http://www.healthresearchforum.org.uk/reports/sunbook.pdf (last accessed: 11/02/2015) 2006

2 Pearce SHA, Cheetham TD. Diagnosis and management of Vitamin D deficiency. BMJ 2010; 340: b5664

3 Pludowski P 1, Holick MF, Pilz S, Wagner CL, Hollis BW, Grant WB, Shoenfeld Y, Lerchbaum E, Llewellyn DJ, Kienreich K, Soni M. Vitamin D effects on musculoskeletal health, immunity, autoimmunity, cardiovascular disease, cancer, fertility, pregnancy, dementia and mortality - a review of recent evidence. Autoimmun Rev 2013; 12: 976-989

4 Gibb D. Rickets and the crippled child: an historical perspective. J R Soc Med 1994; 87: 729-732

5 Holick MF. Vitamin D deficiency. N Engl Journal Med 2007; 357: 266-281
6 Holick MF. Sunlight and vitamin D for bone health and prevention of autoimmune diseases, cancers and cardiovascular disease. Am J Clin Nutr 2004; 80: suppl 1678S-1688S

7 Holick MF. Vitamin D: A millennium perspective. J Cell Biochem 2003; 88: 296-307

8 Mawer EB, Hayes ME, Heys SE, Davies M, White A, Stewart MF, Smith GN. Constitutive synthesis of 1,25 -dihydroxyvitamin $D_{3}$ by a human small cell lung cell line. J Clin Endcrinol Metab 1994; 79: 554-560

9 Heald $A H$, Anderson SG, Scargill JJ, Short AD, Holland D, Livingston $M$, Fryer AA, Donn RP. Measuring vitamin D levels: surrogates are insufficient. Int J Clin Pract 2015; 69: 131-135

10 Webster $C$. Relationship of total 25-OH vitamin D concentrations to Indices of Multiple Deprivation: geoanalysis of laboratory results. Ann Clin Biochem 2013; 50: 31-38

11 Heaney RP, Dowell MS, Hale CA, Bendich A. Calcium absorption varies within the reference range for 25-hydroxyvitamin D. J Am Coll Nutr 2003; 22: 142-146

12 Henderson L, Irving K, Gregory J, Bates CJ, Prentice A, Perks J, Swan G, Farron M. The National Diet and Nutrition Survey: adults aged 19 to 64 years. Vol 3: Vitamin and mineral uptake and urinary analyses. The Stationery Office; London: 2003

13 Holick MF, Binkley NC, Bischoff-Ferrari HA, Gordon CM, Hanley DA Heaney RP, Murad MH, Weaver CM. Evaluation, treatment, and prevention of vitamin D deficiency: an Endocrine Society clinical practice guideline. J Clin Endocrinol Metab 2011; 96: 1911-1930

14 Chuck A, Todd J, Diffey B. Subliminal ultraviolet-B radiation for the prevention of vitamin $D$ deficiency in the elderly: a feasibility study. Photodermatol Photoimmunol Photomed 2001; 17: 168-171 